\title{
89. The Effect of Ions on the Steady and Generator Potential of Frog Muscle Spindles
}

\author{
By Fumio Iтo \\ Department of Physiology, School of Dentistry, Aichi-Gakuin \\ University, Nagoya
}

(Comm. by Yas Kuno, M. J. A., May 12, 1969)

A steady potential has been recorded from the frog muscle spindle by Ito $^{1,2)}$ by means of a paraffin gap method. The present study was intended to determine a role of ions in contributing to the steady potential and the generator potential of the muscle spindle.

Fourty sciatic nerve-sartorius muscle preparations, excised from frogs (Rana nigromaculata) weighing about $40 \mathrm{~g}$, were employed as materials in the experiments. The afferent fiber was isolated in its intramuscular course until the capsule of a spindle receptor was cleared, but its capsule and intrafusal muscle bundle were kept intact. The isolated receptors were identified microscopically and their supplying nerve by the conduction velocities.

The paraffin gap method for recording the potentials along the nerve terminal was described in detail in earlier papers.1,2) The potential differences led with a pair of calomel electrodes were displayed on one beam of a dual beam oscilloscope through a high input impedance DC amplifier. Negativity at the sensory ending of the nerve relative to the proximal nerve stump, which implies that a current flows from the proximal to the ending along the external longitudinal resistance $(2-3 \mathrm{M} \Omega)$ of the axon at the paraffin pool, was displayed as an upward deflection.

The muscle was stretched by $2 \mathrm{~mm}$ from its in situ length at a velocity of $30 \mathrm{~mm} / \mathrm{sec}$. The tension of the muscle was detected with a mechanoelectric transducer (RCA 5734), and displayed on one of the beams of the oscilloscope. The compositions of the isotonic solutions used in these experiments were the same as those described by Adrian and Freygang. ${ }^{3)}$ All the experiments were made in summer at room temperature of $23-27^{\circ} \mathrm{C}$.

When a muscle was placed at its in situ length in the normal Ringer's solution, the nerve endings were always electrically positive by 2 to $3 \mathrm{mV}$ against the proximal part of the axon. The presence of this steady potential implies that an anelectrotonic current of approximately $10^{-9} \mathrm{~A}$ always flows from the nerve ending to the proximal part of the axon. During stretch of the muscle, a slow 

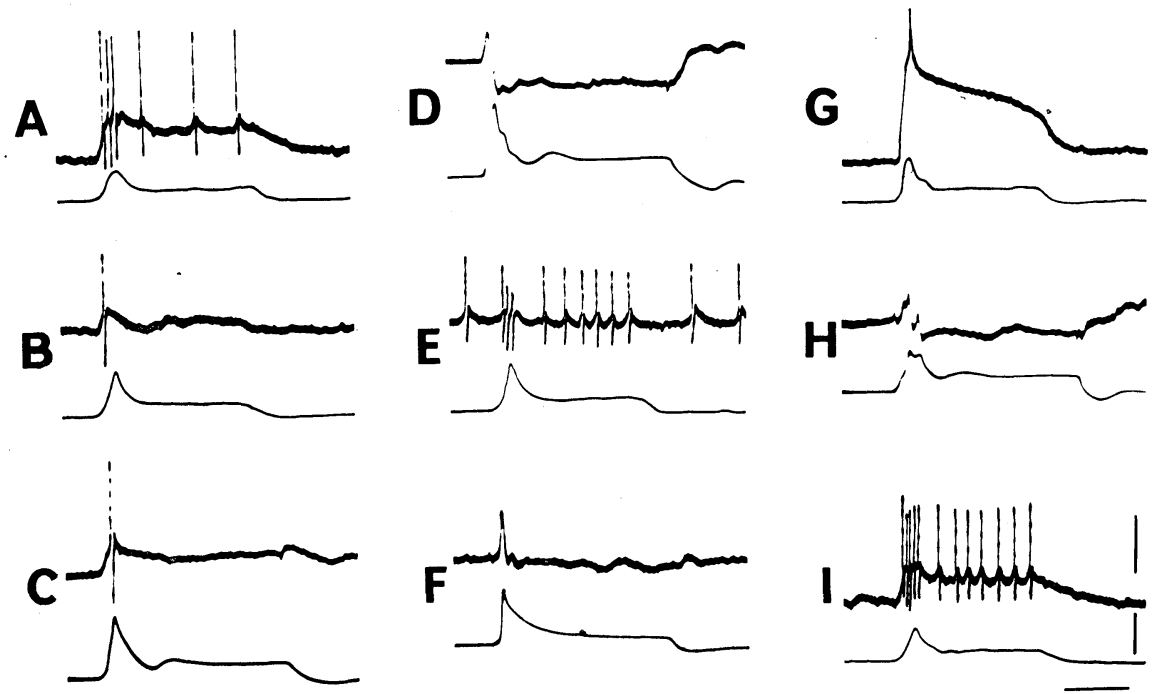

Fig. 1. Responses of spindle receptors (upper traces) and tension curves of the muscles (lower traces) during stretching the muscle by $2 \mathrm{~mm}$ from the in situ length at a velocity of $30 \mathrm{~mm} / \mathrm{sec}$. A: A record in the normal Ringer's solution. B, C, and D: Records at 10 minutes after immersing the receptor in Ringer's solutions in which the sodium had been replaced with an equivalent lithium, choline and potassium respectively. $\mathrm{E}$ and $\mathrm{F}$ : Records at 3 and 10 minutes respectively after immersing the receptor in a Ringer's solution in which the chloride had been replaced with an equivalent sulfate. $\mathrm{G}$ and $\mathrm{H}$ : Records at 1 and 15 minutes respectively after immersing the receptor in an isotonic sucrose solution. I: A record at 2 minutes after the receptor was returned into the normal Ringer's solution. Calibration: $0.5 \mathrm{mv}, 0.3 \mathrm{~g}$, and $30 \mathrm{msec}$.

catelectrotonic deflection (generator potential) occurred, on which several spikes were superimposed (Fig. 1A). After sodium ions in the normal Ringer's solution had been replaced by lithium or choline, the positive steady potential remained unchanged, but the amplitude of the generator potential decreased to $30-50 \%$ of the normal value and spike discharges disappeared 10 minutes after the replacement (Fig. 1B and C). The similar results were also observed after sodium had been replaced by barium. These results show that sodium permeability contributes to the generation of the generator potential but not of the steady potential. The replacement of the sodium by potassium resulted in the negative steady potential of $8-10 \mathrm{mV}$ and in disappearance of the generator potential or a positive generator potential without spikes (Fig. 1D). It is considered that the membrane potential at the sensory nerve ending may be reduced to or beyond the reversal potential for the generator potential. When chloride in Ringer's solution was replaced by sulfate, a negative steady potential of $1-1.5 \mathrm{mV}$ was observed, but no reversed 
generator potential was detected. For 2-5 minutes after the replacement of the solution, frequent spike discharges appeared spontaneously or superimposed on a reduced generator potential during stretch of the muscle (Fig. 1E). Thereafter the spike discharges and the generator potential disappeared, an artificial deflection remaining at a dynamic phase of the muscle stretch (Fig. 1F). After the replacement of the ions mentioned above, the resistance across the paraffin gap remained unchanged. However, when all the Ringer's solution was replaced by an isotonic sucrose solution, the resistance increased to 8-10 $\mathrm{M} \Omega$. The replacement gave rise also an increase of up to $8-10 \mathrm{mV}$ in the positive steady potential and of up to $4-5 \mathrm{mV}$ in amplitude of the generator potential, while the frequency and amplitude of the spike decreased (Fig. 1G). The sucrose solution probably reduced short-circuit currents along the axonal branches in the capsule or along the axon between the capsule and the paraffin gap. Ten minutes after the replacement, the steady potential became to negativity of $1-1.5 \mathrm{mV}$, while spikes disappeared and the generator potential was abolished or sometimes reversed (Fig. 1H). In all the above experiments, the responses reappeared rapidly upon reimmersion of the preparation in Ringer's solution though full recovery seldom occurred (Fig. 1I).

The experiments on sulfate and sucrose suggest that chloride ions have a role in the generation of the positive steady potential, and that the generator potential depends upon the amount of the steady potential. Takagi, Wyse, and Yajima ${ }^{4)}$ have observed that the positive olfactory receptor potential in the frog depends primarily upon the influx of chloride ions through the olfactory receptive membrane. Ottoson ${ }^{5), 6)}$ and Calma ${ }^{7)}$ have shown that receptor potentials in procainized and strongly stimulated spindles in the frog are decreased in amplitude by $20-30 \%$ and $70-80 \%$, respectively, by the replacement of sodium by choline. They have considered that the production of the receptor potential depends on the presence not only of sodium but of other ions, especially calcium. It is assumed that the sensory membrane of the frog muscle spindle possesses a large permeability to chloride ion and that the generator potential is produced because of an increase of permeabilities to sodium, potassium and probably other ions during stretch of the membrane, as shown in Pacinian corpuscle by Diamond, Gray, and Inman. ${ }^{8}$ )

Acknowledgment. I am indebted to Prof. M. Sato in the Department of Physiology, Kumamoto University Medical School, for his helpful discussion and for his correction of English manuscript. 


\section{References}

1) Ito, F.: Proc. Japan Acad., 44, 852-855 (1968).

2) - Jap. J. Physiol., 19 (1969) (in press).

3) Adrian, R. H., and Freygang, W. H.: J. Physiol., 163, 61-103 (1962).

4) Takagi, S. F., Wyse, G. A., and Yajima, T.: J. Gen. Physiol., 50, 473-489 (1966).

5) Ottoson, D.: J. Physiol., 171, 109-118 (1964).

6) - : J. Physiol., 178, 68-74 (1965).

7) Calma, I.: J. Physiol., 177, 31-41 (1965).

8) Diamond, J., Gray, J. A. B., and Inman, D. R.: J. Physiol., 142, 382-394 (1958). 